\title{
Lymphocyte-Rich Gastric Cancer: Associations with Epstein-Barr Virus, Microsatellite Instability, Histology, and Survival
}

Karen L. Grogg, M.D., Christine M. Lohse, B.S., V. Shane Pankratz, Ph.D., Kevin C. Halling, M.D., Ph.D., Thomas C. Smyrk, M.D.

Division of Anatomic Pathology, Department of Laboratory Medicine and Pathology (KLG, KCH, TCS) and the Division of Biostatistics, Department of Health Sciences Research (CML, VSP), Mayo Clinic, Rochester, Minnesota

Lymphocyte-rich gastric carcinomas may have a better prognosis than cancers without a pronounced host inflammatory response. Two subsets of gastric cancer-Epstein-Barr virus-positive and microsatellite instability high-have been associated with a lymphocyte-rich phenotype. We assessed relationships between tumor-infiltrating lymphocytes, Epstein-Barr virus status, microsatellite instability status, and cancer-specific survival in 110 resected gastric cancers. Seven patients had Epstein-Barr virus-positive cancer, including 4 (3.7\%) of 107 consecutive patients. Tumors from 17 patients $(16 \%)$ were designated microsatellite instability high on the basis of negative immunohistochemical staining for MLH1; all tumors had intact expression of MSH2 and MSH6. Epstein-Barr viruspositive cancers had increased tumor-infiltrating lymphocytes compared with Epstein-Barr virusnegative cancers (median 450/10 HPF versus 21/10 HPF, $P<.001)$. Microsatellite instability-high cancers also had increased tumor-infiltrating lymphocytes compared with non-microsatellite instabilityhigh cancers (median 150/10 HPF versus 20/HPF, $P$ $<$.001). Microsatellite instability-high cancers affected older patients and were more likely to be intestinal in the Lauren classification and expanding in the Ming classification. By univariate analysis, decreased risk of death from gastric cancer was significantly associated with low tumor stage, expanding growth pattern, increasing tumorinfiltrating lymphocyte count, and microsatellite in-

Copyright (C) 2003 by The United States and Canadian Academy of Pathology, Inc.

VOL. 16, NO. 7, P. 641, 2003 Printed in the U.S.A.

Date of acceptance: April 29, 2003.

Presented in part at the 91st Annual Meeting of the United States and Canadian Academy of Pathology, Chicago, IL, February 26, 2002.

Address reprint requests to: Thomas C. Smyrk, M.D., Department of

Laboratory Medicine and Pathology, 200 First Street SW, Rochester, MN

55905; fax: 507-284-1599; e-mail: smyrk.thomas@mayo.edu.

DOI: 10.1097/01.MP.0000076980.73826.CO stability-high status. High tumor-infiltrating lymphocyte count and microsatellite instabilityhigh status retained statistical significance as favorable prognostic factors after adjustment for tumor stage in multivariate analysis. Tumor-infiltrating lymphocyte count retained statistical significance as a favorable prognostic factor after adjustment for microsatellite instability-high status; but microsatellite instability-high status did not remain a significant independent prognosticator after adjustment for tumor-infiltrating lymphocyte count. The association between microsatellite instability-high cancers and high tumor-infiltrating lymphocyte counts may account for the association of microsatellite instability-high gastric cancers with improved survival.

KEY WORDS: Epstein-Barr virus, Gastric carcinoma, Microsatellite instability, Tumor-infiltrating lymphocytes.

Mod Pathol 2003;16(7):641-651

Watanabe et al. (1) described a specific type of lymphocyte-rich gastric cancer, termed gastric carcinoma with lymphoid stroma, that had a better prognosis than other gastric carcinomas. Subsequent reports, some using the synonyms lymphoepithelioma-like carcinoma or medullary carcinoma of the stomach, confirmed the observation (1-5). Strictly defined, gastric carcinoma with lymphoid stroma shows sharply demarcated margins and non-desmoplastic stroma reminiscent of lymphoid tissue, with small nests of cancer cells uniformly distributed throughout the lymphoid stroma. It is not known whether less stereotypic patterns of lymphocyte infiltration are associated with survival differences.

Two subsets of gastric carcinoma can have large numbers of lymphocytes: Epstein-Barr virus (EBV)positive cancers (5-12) and cancers with high levels 
of microsatellite instability (13-16). EBV can be demonstrated in the tumor cells in $1.8-18 \%$ of sporadic gastric carcinomas, and the prevalence is significantly higher $(>80 \%)$ in gastric carcinoma with lymphoid stroma $(4,5,7,10,17-20)$. The relationship between EBV status and survival is not clear; it has been suggested that a survival advantage is seen only in those tumors that can be categorized as gastric carcinoma with lymphoid stroma, and that EBV-positivity itself does not confer a more favorable prognosis $(4,5,17)$.

Instability involving microsatellite DNA sequences was originally recognized in tumors from patients with hereditary non-polyposis colon carcinoma, but has subsequently been observed in a subset of sporadic tumors from various sites including colon, stomach and endometrium $(13,14,16$, 21-27). High levels of microsatellite instability result from defective function of DNA mismatch repair enzymes, usually hMLH1or hMSH2, rarely hMSH6 $(15,22,28)$. The reported prevalence of high microsatellite instability in gastric carcinoma ranges from $7-39 \%$, with apparent geographic variability $(15,16,23,27,29-31)$. Most studies have suggested improved survival compared with tumors with stable microsatellite sequences or low levels of microsatellite instability $(13,16,26,27,31)$.

The gold standard method to assess microsatellite instability is PCR analysis of microsatellite loci, with instability at $>30 \%$ of loci indicating defective DNA mismatch repair. Recent studies in colorectal carcinoma have shown that immunohistochemistry using antibodies directed against DNA mismatch repair enzymes hMLH1 and hMSH2 can be used as a surrogate marker for MSI status. Lack of expression of one of these proteins by immunohistochemistry has essentially perfect specificity for microsatellite instability-high status $(32,33)$. The sensitivity of immunohistochemistry for detecting the microsatellite instability-high phenotype is also very high, having been reported as $92 \%$ in colorectal carcinoma (34). The sensitivity is likely even higher in gastric carcinoma, where the majority of microsatellite instability-high cases result from hypermethylation of the hMLH1 gene promoter, a situation that will always lead to absent expression of the protein $(32,33,35)$.

We studied clinicopathologic features and outcome in 110 resected gastric carcinomas to better define the relationships between lymphoid infiltrate, histology, EBV status, MSI status and prognosis. For the reasons outlined above, MSI status was assessed using immunohistochemistry for DNA mismatch repair enzymes. The lymphoid infiltrate was quantified as tumor-infiltrating lymphocytes per 10 high-power microscopic fields to better illustrate the association between tumor infiltrating lymphocyte count and outcome in gastric cancer.

\section{MATERIALS AND METHODS}

\section{Case Selection}

Mayo Clinic files were searched for patients who underwent partial or complete gastric resection between 1990 and 1998. Tumors of the gastric cardia were excluded from this analysis. One hundred seven cases were identified for which histologic material was available. Three additional cases of known EBV-positive gastric carcinoma from the consultation files were added to the series. Clinical information regarding follow-up was obtained by chart review and phone contact with primary physicians. This study was approved by the Mayo Clinic Institutional Review Board, and all patients consented for use of their medical records for research.

\section{Histologic Evaluation}

Two pathologists (KLG, TCS) independently analyzed the hematoxylin and eosin-stained slides from each case and assessed histologic grade, Lauren and Ming classifications, gastric carcinoma with lymphoid stroma categorization (according to the criteria of Watanabe et al., 1), and tumorinfiltrating lymphocytes per 10 HPF (Nikon E600; field diameter $0.52 \mathrm{~mm}$ ). Histologic evaluation was done without prior knowledge of the microsatellite instability status and EBV status of the tumor. Any discrepancy was reviewed to reach consensus. To be included in the tumor-infiltrating lymphocyte count, the lymphocyte had to be clearly identifiable as a lymphocyte, and be in direct contact with tumor cells (Fig. 1). Lymphocytes present in the stroma but not in contact with tumor cells were not counted.

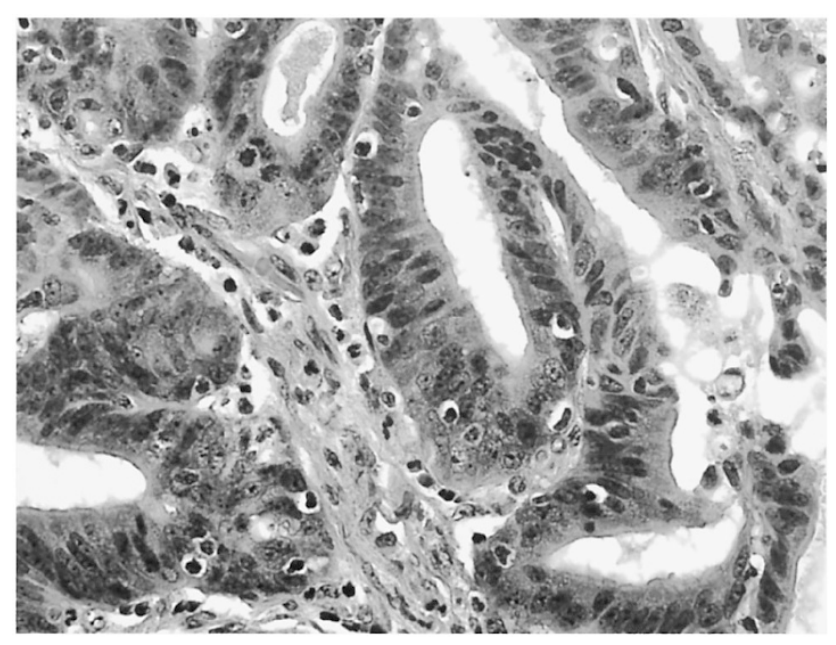

FIGURE 1. Gastric cancer with abundant tumor-infiltrating lymphocytes. Lymphocytes are intimately associated with tumor cells and have a characteristic perinuclear white halo. Stromal lymphocytes are not included in the tumor-infiltrating lymphocyte count (H\&E; original magnification, $600 \times$ ). 


\section{In Situ Hybridization for EBV}

EBV RNA in situ hybridization was performed on paraffin sections from each case. Oligonucleotides complementary to a portion of the EBV early RNAs (EBER1 and EBER2) were applied using the procedure of Chang et al. (36). A case was determined to be positive if intranuclear staining was observed in gastric tumor cells. Cases with scattered lymphocytes containing EBV genome were not scored as positive.

\section{Evaluation of Microsatellite Instability Status}

Immunohistochemical staining for hMLH1, hMSH2 and hMSH6 was performed as described by Halling and Roche (37). The antibody to hMSH2 (Clone FE11, $0.5 \mu \mathrm{g} / \mathrm{mL}$, Oncogene Science) is a mouse monoclonal antibody generated with a carboxy-terminal fragment of the hMSH2 protein, whereas the hMLH1 antibody (clone G168-728, 1 $\mu \mathrm{g} / \mathrm{mL}$, Pharmingen, San Diego, CA) is a mouse monoclonal antibody that was prepared with fulllength hMLH1 protein. The antibody to hMSH6 was clone $44(0.5 \mathrm{mg} / \mathrm{mL}$, Transduction Laboratories, Lexington, KY). Lymphocytes and normal epithelium exhibit strong nuclear staining for hMLH1, hMSH2 and hMSH6 and served as positive internal controls.

\section{Statistical Methods}

Comparisons of clinicopathologic tumor features were assessed using Wilcoxon rank sum, chisquare, and Fisher's exact tests. All tests were twosided and $P$ values $<.05$ were considered statistically significant.

The Kaplan-Meier method was used to estimate cancer-specific survival. Duration of follow-up was defined from the date of diagnosis to the date of death or last follow-up. Univariate and multivariate Cox proportional hazards regression models were fit to assess which clinicopathologic features were associated with cancer-specific survival. The relationships between these features and cancerspecific survival were summarized with risk ratios and $95 \%$ confidence intervals $(95 \% \mathrm{CI})$.

\section{RESULTS}

The clinicopathologic features are summarized in Table 1. A total of seven tumors were positive for EBV by in situ hybridization (Fig. 2), including 4 of the 107 consecutive cases (3.7\%) and the 3 consultation cases added to the series because they were known to be EBV-positive. A comparison of clinicopathologic features by EBV status is shown in Table 2. EBV status was significantly associated with the number of tumor-infiltrating lymphocytes
TABLE 1. Clinicopathologic Features of Gastric Carcinoma Cases

\begin{tabular}{|c|c|}
\hline Feature & $\begin{array}{c}\text { Mean (SD) } \\
\text { Median } \\
\text { Range }\end{array}$ \\
\hline \multirow[t]{3}{*}{ Age at diagnosis (years) } & $68.4(12.4)$ \\
\hline & 70.5 \\
\hline & $38-90$ \\
\hline \multicolumn{2}{|l|}{ Sex } \\
\hline Female & $38(34.5)$ \\
\hline Male & $72(65.5)$ \\
\hline \multicolumn{2}{|l|}{ Tumor histologic differentiation } \\
\hline Well & $3(2.7)$ \\
\hline Moderate & $32(29.1)$ \\
\hline Poor & $75(68.2)$ \\
\hline \multicolumn{2}{|l|}{ Primary tumor } \\
\hline $\mathrm{T} 1$ & $6(5.5)$ \\
\hline $\mathrm{T} 2$ & 19 (17.3) \\
\hline T3 & $74(67.3)$ \\
\hline $\mathrm{T} 4$ & $11(10.0)$ \\
\hline \multicolumn{2}{|l|}{ Regional lymph nodes } \\
\hline NX & $1(0.9)$ \\
\hline No & $28(25.5)$ \\
\hline N1 & $50(45.5)$ \\
\hline $\mathrm{N} 2$ & $21(19.1)$ \\
\hline N3 & $10(9.1)$ \\
\hline \multicolumn{2}{|l|}{ Distant metastases } \\
\hline M0 & $81(73.6)$ \\
\hline M1 & $29(26.4)$ \\
\hline \multicolumn{2}{|l|}{ Tumor location } \\
\hline Unknown & $25(22.7)$ \\
\hline Body & $19(17.3)$ \\
\hline Distal & $47(42.7)$ \\
\hline Entire & $11(10.0)$ \\
\hline Proximal & $8(7.3)$ \\
\hline \multicolumn{2}{|l|}{ Lauren classification } \\
\hline Diffuse & $55(50.0)$ \\
\hline Intestinal & $51(46.4)$ \\
\hline Mixed & $4(3.6)$ \\
\hline \multicolumn{2}{|l|}{ Ming classification } \\
\hline Expanding & $43(39.1)$ \\
\hline Infiltrative & $67(60.9)$ \\
\hline \multicolumn{2}{|l|}{$\begin{array}{l}\text { Gastric carcinoma with } \\
\text { lymphoid stroma }\end{array}$} \\
\hline No & $104(94.5)$ \\
\hline Yes & $6(5.5)$ \\
\hline \multicolumn{2}{|l|}{ EBV status } \\
\hline Negative & $103(93.6)$ \\
\hline Positive & $7(6.4)$ \\
\hline \multicolumn{2}{|l|}{ MLH-1 status } \\
\hline $\begin{array}{l}\text { Negative (microsatellite } \\
\text { instability high) }\end{array}$ & $17(15.5)$ \\
\hline $\begin{array}{l}\text { Positive (non-microsatellite } \\
\text { instability high) }\end{array}$ & $93(84.5)$ \\
\hline
\end{tabular}

per $10 \mathrm{HPF}$. The median number of tumorinfiltrating lymphocytes per $10 \mathrm{HPF}$ for EBV negative tumors was 21, compared with 450 for EBV positive tumors $(P<.001)$.

Six cases were designated as gastric carcinoma with lymphoid stroma (Fig. 3), including 3 of the 107 consecutive cases $(2.8 \%)$. Three of the patients (42.9\%) with EBV positive tumors were designated as gastric carcinoma with lymphoid stroma, compared with 3 patients $(2.9 \%)$ with EBV negative tumors $(P<.001)$. By definition, gastric carcinoma with lymphoid stroma tumors demonstrated a pronounced lymphocytic infiltrate surrounding the cancer cell nests. Tumor-infiltrating lymphocytes in 


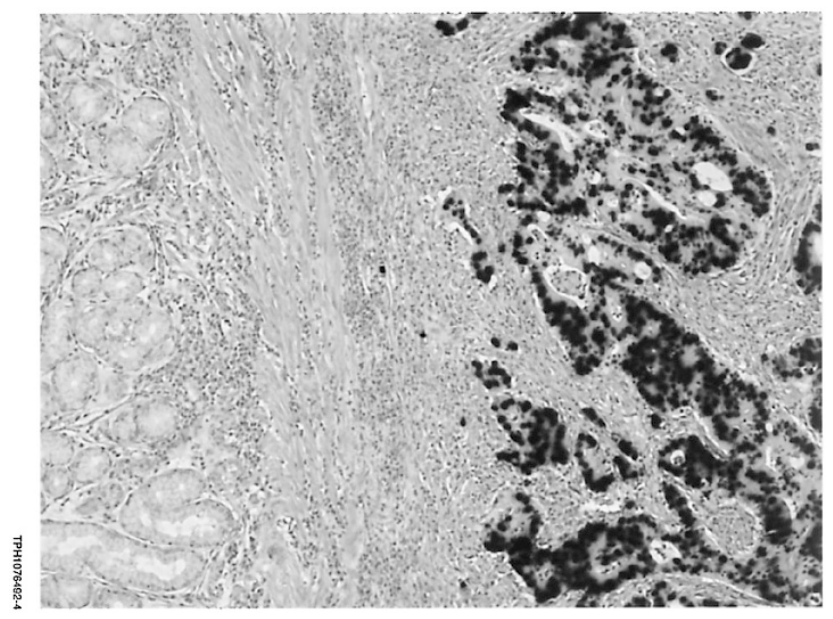

FIGURE 2. EBV RNA detected in gastric cancer nuclei by in situ hybridization. The overlying non-neoplastic epithelium lacks staining (in situ hybridization for EBER1 and EBER2; original magnification, $100 \times)$.

gastric carcinoma with lymphoid stroma ranged from 300 to 800 per $10 \mathrm{HPF}$, with a mean of 525 .

Seventeen of the 110 tumors (16\%) showed complete loss of nuclear staining with antibody to hMLH1 and were therefore designated as microsatellite instability high (Fig. 4). None of the cases lacked staining for hMSH2 or hMSH6. A comparison of the clinicopathologic features by hMLH1 status is shown in Table 3. Patients with microsatellite instability-high tumors were significantly older compared with those with non-microsatellite instability-high tumors (median 77 y versus 69 y; $P$ $=.016$ ). Those with microsatellite instability-high tumors also had significantly higher tumorinfiltrating lymphocytes per 10 HPF compared with patients with non-microsatellite instability-high tumors (median 150 versus $20 ; P<.001$ ). The distribution of tumor-infiltrating lymphocytes in microsatellite instability-high and EBV positive tumors is displayed in Fig. 5. Microsatellite instability high tumors were also more likely to be of lower tumor grade $(P=.018)$, less likely to have distant metastases $(P=.039)$ and more likely to be intestinal type according to the Lauren classification $(P=.030)$ compared with tumors that were nonmicrosatellite instability high. Lastly, there was a significant association between microsatellite instability status and Ming classification in that most of the microsatellite instability-high tumors (94\%) were classified as expanding compared with only 27 (29\%) of the non-microsatellite instability-high tumors $(P<.001)$.

Sixty patients died from gastric cancer. The average (SD) time from diagnosis to death from cancer was 18.4 (16.8) months, ranging from 1 to 70 months. Among the 50 patients who died from other causes or were still alive at last follow-up, the average (SD) time from diagnosis to last follow-up was 37.1 (28.8) months, ranging from 1 to 131 months. The estimated cancer-specific survival rates at $12,24,36$, and 48 months were $72.1 \%$, $56.5 \%, 48.9 \%$, and $41.5 \%$, respectively.

Univariate associations between clinicopathologic features and cancer-specific survival are shown in Table 4. The number of tumor-infiltrating lymphocytes per $10 \mathrm{HPF}$ was significantly associated with death from gastric cancer. Because the tumor-infiltrating lymphocyte distribution was severely skewed, this feature was analyzed on the natural logarithmic scale. Each 1-unit increase in the number of tumor-infiltrating lymphocytes per $10 \mathrm{HPF}$ on the natural logarithmic scale (or an increase by a power of 2.72 tumor-infiltrating lymphocytes per $10 \mathrm{HPF}$ on the original scale) decreased the risk of death from gastric cancer by $27 \%$ $(P=.001)$. The univariate association of this feature with cancer-specific survival is shown in Figure 6.

Other parameters showing statistically significant association with survival were microsatellite instability status, tumor stage and Ming classification. Patients with microsatellite instability-high tumors were 2.8 times less likely to die from gastric cancer compared with those with non-microsatellite instability-high tumors $(P=.021)$. Patients with stage IV tumors were 11 times more likely to die from gastric cancer compared with those with stage I tumors $(P$ $<$.001). Patients with Stage IIIa or IIIb tumors were 5 times more likely to die from their disease compared with those with stage I tumors $(P=.026)$. The relationship between tumor stage and cancerspecific survival is shown in Figure 7. Patients with infiltrative tumors according to the Ming classification were three times more likely to die from their disease compared with patients with expanding tumors $(P<.001)$.

Microsatellite instability-high status and tumorinfiltrating lymphocyte count retained a significant association with survival after adjusting for tumor stage (Table 4). Because these two variables were also associated with each other, multivariate analysis was performed to determine their independent effect upon survival (Table 5). A significantly decreased risk of death from gastric cancer with increasing tumor-infiltrating lymphocyte count was apparent even after adjusting for microsatellite instability-high status $(P=.013)$. In contrast, the association between microsatellite instability status and cancer-specific survival was not statistically significant after adjusting for tumor-infiltrating lymphocyte count $(P=.125)$.

\section{DISCUSSION}

Lymphocyte-rich gastric carcinoma has been associated with a survival advantage compared with 


\begin{tabular}{|c|c|c|c|c|}
\hline \multirow[b]{2}{*}{ Feature } & \multicolumn{3}{|c|}{ EBV Status } & \multirow[b]{2}{*}{ p-value } \\
\hline & Negative $N=103$ & $\begin{array}{c}\text { Mean (SD) } \\
\text { Median } \\
\text { Range }\end{array}$ & Positive $\mathrm{N}=7$ & \\
\hline \multirow[t]{2}{*}{ Age at diagnosis (years) } & $68.8(12.0)$ & & $61.1(16.7)$ & 0.182 \\
\hline & $\begin{array}{l}71 \\
39-90\end{array}$ & & $\begin{array}{l}65 \\
38-86\end{array}$ & \\
\hline \multirow[t]{4}{*}{ Tumor infiltrating lymphocytes per $10 \mathrm{HPF}$} & $79.9(145.2)$ & & $442.9(181.3)$ & $<0.001$ \\
\hline & 21 & & 450 & \\
\hline & $0-800$ & & $250-800$ & \\
\hline & & N (\%) & & \\
\hline \multicolumn{5}{|l|}{ Sex } \\
\hline Female & $38(36.9)$ & & $0(0.0)$ & 0.093 \\
\hline Male & $65(63.1)$ & & $7(100.0)$ & \\
\hline \multicolumn{5}{|l|}{ Tumor-infiltrating lymphocytes per 10 HPF } \\
\hline $0-5$ & $27(26.2)$ & & $0(0.0)$ & $<0.001$ \\
\hline $6-29$ & $29(26.2)$ & & $0(0.0)$ & \\
\hline 30-99 & $25(24.3)$ & & $0(0.0)$ & \\
\hline$\geq 100$ & $24(23.3)$ & & $7(100.0)$ & \\
\hline \multicolumn{5}{|l|}{ Tumor histologic differentiation } \\
\hline Well & $3(2.9)$ & & $0(0.0)$ & 1.00 \\
\hline Moderate & $30(29.1)$ & & $2(28.6)$ & \\
\hline Poor & $70(68.0)$ & & $5(71.4)$ & \\
\hline \multicolumn{5}{|l|}{ Primary tumor } \\
\hline $\mathrm{T} 1$ & $6(5.8)$ & & $0(0.0)$ & 0.629 \\
\hline $\mathrm{T} 2$ & 19 (18.5) & & $0(0.0)$ & \\
\hline T3 & $68(66.0)$ & & $6(85.7)$ & \\
\hline $\mathrm{T} 4$ & $10(9.7)$ & & $1(14.3)$ & \\
\hline \multicolumn{5}{|l|}{ Regional lymph nodes } \\
\hline NX & $1(1.0)$ & & $0(0.0)$ & 0.642 \\
\hline No & $26(25.2)$ & & $2(28.6)$ & \\
\hline N1 & $48(46.6)$ & & $2(28.6)$ & \\
\hline $\mathrm{N} 2$ & 19 (18.5) & & $2(28.6)$ & \\
\hline N3 & $9(8.7)$ & & $1(14.3)$ & \\
\hline \multicolumn{5}{|l|}{ Distant metastases } \\
\hline M0 & 75 (72.8) & & $6(85.7)$ & 0.673 \\
\hline M1 & $28(27.2)$ & & $1(14.3)$ & \\
\hline \multicolumn{5}{|l|}{ Tumor stage } \\
\hline Ia & $6(5.8)$ & & $0(0.0)$ & 0.225 \\
\hline Ib & $9(8.7)$ & & $0(0.0)$ & \\
\hline II & $13(12.6)$ & & $2(28.6)$ & \\
\hline IIIa & $32(31.1)$ & & $2(28.6)$ & \\
\hline IIIb & $7(6.8)$ & & $2(28.6)$ & \\
\hline IV & $36(35.0)$ & & $1(14.3)$ & \\
\hline \multicolumn{5}{|l|}{ Tumor location } \\
\hline Unknown & $23(22.3)$ & & $2(28.6)$ & 0.605 \\
\hline Body & $19(18.5)$ & & $0(0.0)$ & \\
\hline Distal & $44(42.7)$ & & $3(42.9)$ & \\
\hline Entire & $10(9.7)$ & & $1(14.3)$ & \\
\hline Proximal & $7(6.8)$ & & $1(14.3)$ & \\
\hline \multicolumn{5}{|l|}{ Lauren classification } \\
\hline Diffuse & $50(48.5)$ & & $5(71.4)$ & 0.074 \\
\hline Intestinal & $50(48.5)$ & & $1(14.3)$ & \\
\hline Mixed & $3(2.9)$ & & $1(14.3)$ & \\
\hline \multicolumn{5}{|l|}{ Ming classification } \\
\hline Expanding & 39 (37.9) & & $4(57.1)$ & 0.429 \\
\hline Infiltrative & $64(62.1)$ & & $3(42.9)$ & \\
\hline \multicolumn{5}{|l|}{ Gastric carcinoma with lymphoid stroma } \\
\hline No & $100(97.1)$ & & $4(57.1)$ & $<0.001$ \\
\hline Yes & $3(2.9)$ & & $3(42.9)$ & \\
\hline \multicolumn{5}{|l|}{ MLH-1 Status } \\
\hline Negative (microsatellite instability high) & $17(16.5)$ & & $0(0.0)$ & 0.593 \\
\hline Positive (non-microsatellite instability high) & 86 (83.5) & & $7(100.0)$ & \\
\hline
\end{tabular}

gastric carcinoma without a significant lymphoid infiltrate (1-5). Some have proposed that the inflammatory infiltrate represents an effective host immune response against the tumor cells $(1,4,10)$, an idea supported by the presence of increased antigen-presenting cells in lymphocyte-rich tumors of the stomach (10). In other malignancies (colon, breast and lung cancer, and melanoma) tumorinfiltrating lymphocytes have been shown to bear a cytotoxic T-cell phenotype and are linked positively to survival $(38-42)$.

The molecular characteristics of tumors that elicit an enhanced immune response are undefined, but certain subsets of gastric tumors have 


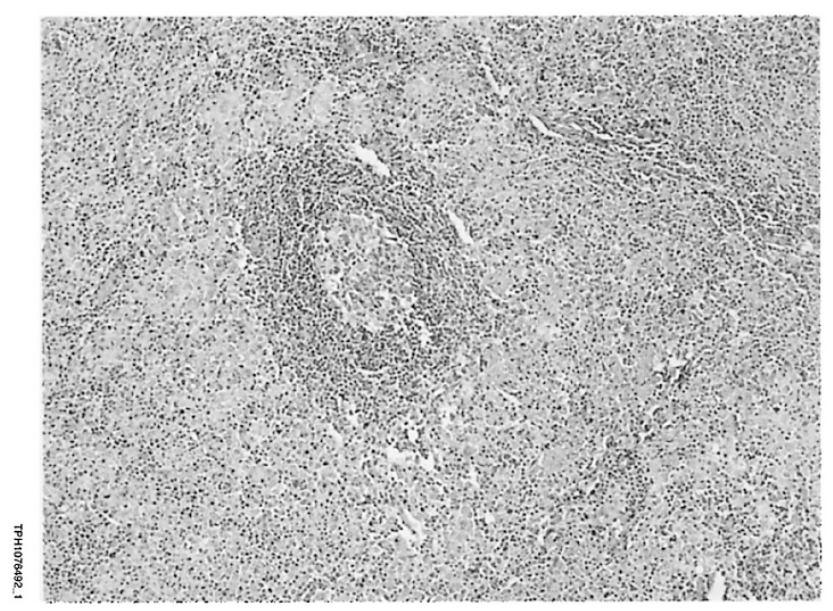

FIGURE 3. Gastric carcinoma with lymphoid stroma. Syncytial nests of tumor cells are distributed in a non-desmoplastic lymphoid stroma. A reactive lymphoid follicle is present in the center of the field (H\&E; original magnification, $100 \times$ ).

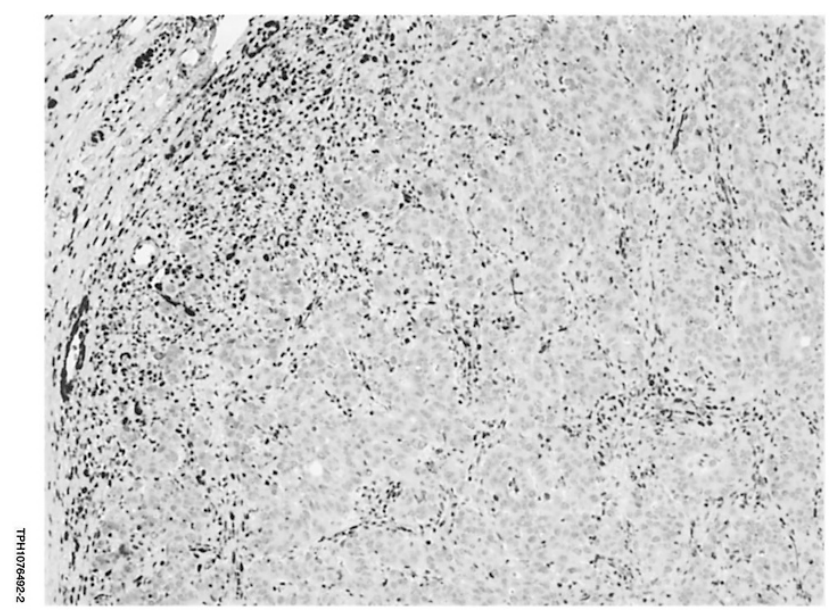

FIGURE 4. Gastric cancer designated as microsatellite instability high on the basis of lack of immunohistochemical staining for the mismatch repair enzyme hMLH-1. Nuclear staining in lymphocytes and stromal cells serves as a positive internal control (original magnification, $100 \times$ ).

been associated with a pronounced lymphoid infiltrate. These subsets, including EBV-positive tumors and microsatellite instability-high tumors, have themselves been variably associated with a survival advantage $(4,5,9,11,13,16,17,26,27,31)$. It has been unclear whether the survival advantage is related to the lymphoid infiltrate, or whether the EBV or microsatellite instability status themselves serve as independent prognosticators. Our study demonstrates that an increasing tumor-infiltrating lymphocyte count is significantly associated with increasingly improved survival in gastric cancer. EBV positivity and microsatellite instability status (after adjusting for tumor-infiltrating lymphocyte count) were not significantly associated with survival.

The prevalence of EBV-positive and microsatellite instability-high tumors in our study is in agreement with previous reports. Of the 107 consecutive patients, 4 (3.7\%) had EBV-positive tumors, which falls within the reported range of $1.8-18 \%(4,5,10$, 17-20). Also in agreement with previous studies, EBV positivity was significantly associated with high tumor-infiltrating lymphocyte counts, with all seven cases showing $>100$ tumor-infiltrating lymphocytes/10HPF. Some reports have suggested that $\mathrm{EBV}$ is associated with improved survival in gastric cancer (4). In contrast, Nakamura et al. demonstrated that patients with gastric carcinoma with lymphoid stroma have an improved prognosis independent of EBV status, suggesting that the lymphoid infiltrate is the critical variable in terms of survival (5). While we had limited numbers of EBVpositive cases, we did not find an association between EBV positivity and improved prognosis.

Using immunohistochemistry as a marker of microsatellite instability status, $16 \%$ of the tumors in our series were microsatellite instability high. The range of microsatellite instability high in gastric cancer from previous reports is $9-39 \%(15,16,23$, $27,29-31)$. All of our microsatellite instability-high cases showed loss of expression of hMLH1; hMSH2 and hMSH6 expression was preserved in all tumors. We screened for false-negative immunostain results by performing PCR-based microsatellite analysis on four tumors with high tumor-infiltrating lymphocyte counts but positive staining for mismatch repair enzymes; all were microsatellite stable (data not shown).

Gastric adenocarcinomas with high levels of microsatellite instability have characteristic clinicopathologic features, including older age, intestinal histotype according to Lauren's classification, an expanding growth pattern according to Ming's classification, and low pTNM stage including less frequent nodal metastases $(13,14,16,22,23,27,30$, 31). Most studies, but not all, have also shown increased lymphocytic infiltration compared with tumors with no or low levels ( $<30 \%$ of loci affected) of microsatellite instability (13-16). Our study confirms the association of microsatellite instabilityhigh tumors with older age, an intestinal histotype and expanding growth pattern. Microsatellite instability-high tumors were represented among all pTNM stages, but they had significantly fewer distant metastases. There was also a strong association between microsatellite instability-high status and increased tumor-infiltrating lymphocytes. The mean tumor-infiltrating lymphocyte count was lower than that associated with EBV positivity (150 versus 450 tumor-infiltrating lymphocytes/10HPF) but significantly higher than the average for nonmicrosatellite instability-high tumors (20 tumorinfiltrating lymphocytes/10HPF). As has been suggested by others, it may be that the accumulation of large numbers of mutations in cells with defective DNA mismatch repair alters the antigenicity of the 


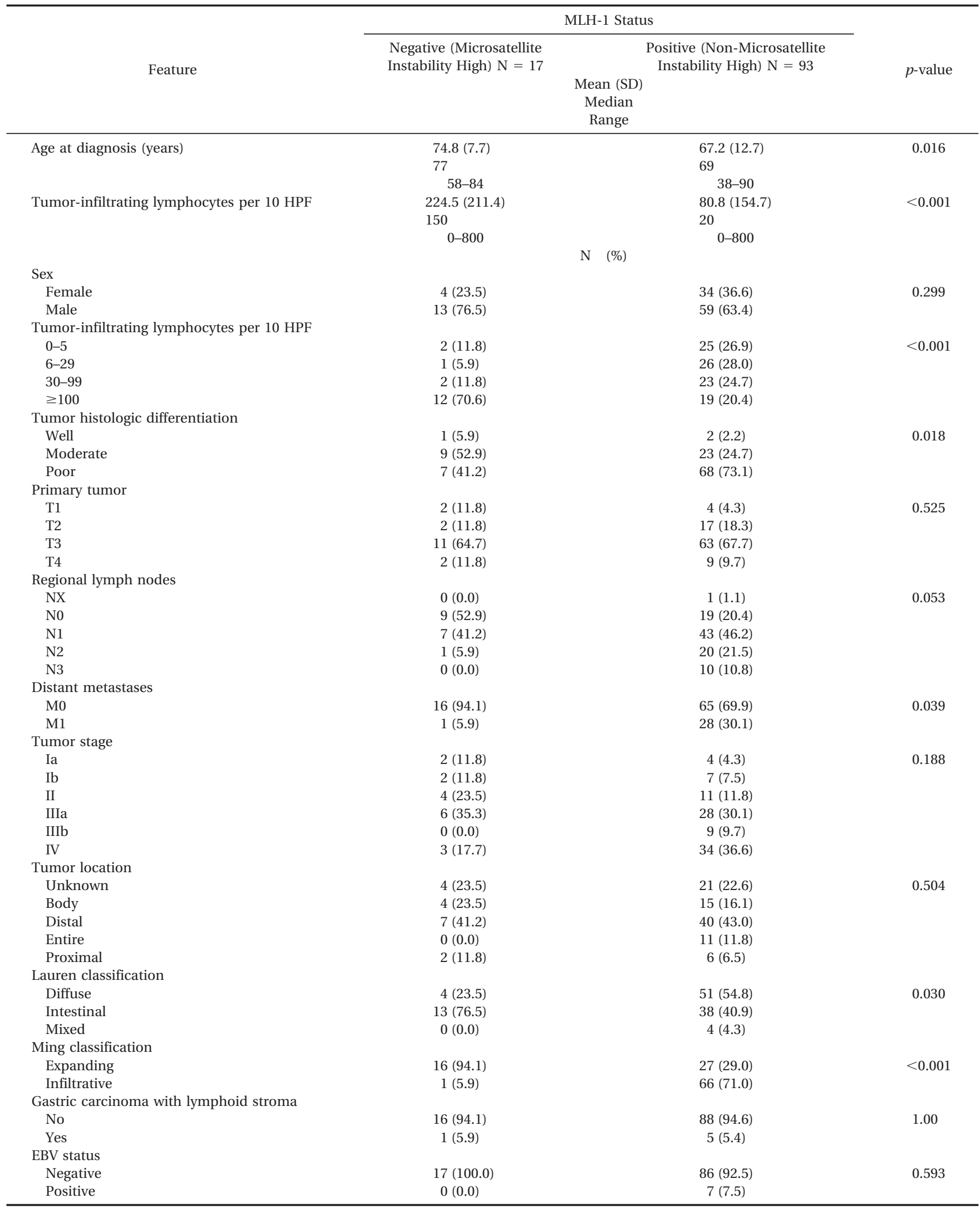

proteins manufactured and in turn leads to an increased immune response to the tumor.

Gastric carcinomas with a microsatellite instability-high phenotype appear to share certain clinicopathologic features with colorectal carcinomas that display this genetic phenotype. Both tumor types have a tendency to present at low pTNM stage with infrequent nodal metastases and also have a better stage-specific prognosis $(16,43)$. Histologically, they both are associated with high numbers of 


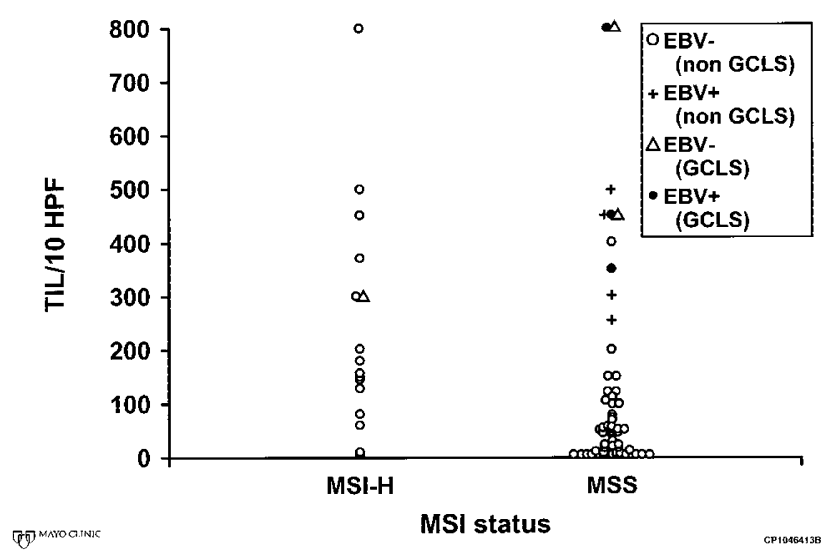

FIGURE 5. Distribution of tumor-infiltrating lymphocyte (TIL) count in microsatellite instability high (MSI-H) versus non-microsatellite instability high (non-MSI-H) gastric cancer. Cases that are positive for EBV and/or display a gastric carcinoma with lymphoid stroma (GCLS) phenotype are indicated (see key).

tumor-infiltrating lymphocytes $(44,45)$. It has been shown that a tumor-infiltrating lymphocyte count of $>5 / 10 \mathrm{HPF}$ has a sensitivity of $93 \%$ and a specificity of $62 \%$ for microsatellite instability-high status in colorectal carcinoma (46). Based on the results of the current study, the presence of tumorinfiltrating lymphocytes in gastric cancer appears to be a less specific and less sensitive marker for microsatellite instability-high status compared with colorectal cancer. Gastric tumors with high tumor-infiltrating lymphocyte counts include both microsatellite instability-high tumors and also EBV-positive tumors, and show a broader range and much higher average number of tumorinfiltrating lymphocytes than colorectal carcinomas.

None of the cases in our series demonstrated concomitant EBV positivity and microsatellite instability-high status. A previous study by Leung et al. (14) found two gastric cancers that were both EBV positive and microsatellite instability high in a series of 79 cases (18 EBV positive, 13 microsatellite instability high). The rarity of this finding suggests that EBV and microsatellite instability are unrelated factors involved in distinct etiologic pathways in gastric carcinogenesis, independently contributing to the induction of a complex host immune response. Although EBV-positive and microsatellite instability-high cancers share the feature of increased tumor-infiltrating lymphocytes, the characteristic clinicopathologic features found only in microsatellite instability-high cancers (as outlined above) further illustrate that the two types are distinct subsets of lymphocyte-rich gastric cancer.

Each of the clinicopathologic features studied was compared with cancer-specific survival by univariate analysis. The strongest associations with cancer-specific survival were seen with pTNM stage, Ming classification, and tumor-infiltrating lymphocyte count. Patients with Stage IV disease had a greater than an 11-fold risk of death compared with those with Stage I disease, and patients with infiltrative tumors had a $>3$-fold risk of death compared with those with expanding tumors. The risk of death from gastric cancer decreased by $27 \%$ with each 1-unit increase in tumor-infiltrating lymphocyte count on the logarithmic scale, or an increase by a power of 2.72 on the original scale. The cancer-specific survival rate at 48 months was $58.8 \%$ for patients with tumor-infiltrating lymphocyte counts $>100 / 10 \mathrm{HPF}$, compared with $34.0 \%$ for patients with tumor-infiltrating lymphocyte counts less than 100/10HPF. The association of tumorinfiltrating lymphocyte count with a decreased risk of death from gastric cancer retained statistical significance even after adjusting for possible compounding variables, including stage and microsatellite instability status.

Microsatellite instability-high tumors also showed a significant association with survival by univariate analysis, which persisted after adjustment for stage in multivariate analysis. However, when adjusted for tumor-infiltrating lymphocyte count, microsatellite instability-high tumors did not show a significant survival advantage. These results suggest that the survival advantage that has been observed in microsatellite instability-high gastric carcinoma is at least in part, if not entirely, attributable to the association of these tumors with increased tumor-infiltrating lymphocytes. Our series did not contain a large number of microsatellite instability-high tumors with low numbers of tumor-infiltrating lymphocytes (only three cases with tumor-infiltrating lymphocyte counts less than the median), and none of these patients died from cancer. Therefore we cannot exclude the possibility that a survival advantage in microsatellite instability-high tumors was masked by the limited sample size. Collection of additional patients in this category may help to further clarify the relationship between these variables.

EBV-positive and microsatellite instability-high tumors accounted for the majority of tumors classified as gastric carcinoma with lymphoid stroma (67\%). Gastric carcinoma with lymphoid stroma demonstrated high numbers of tumor-infiltrating lymphocytes in addition to the characteristic stromal lymphocytic infiltrate. While gastric carcinoma with lymphoid stroma tumors showed a tendency toward markedly improved survival, this did not reach statistical significance, likely because of limited numbers. In light of these findings, gastric carcinoma with lymphoid stroma may represent one end of a spectrum of lymphocyte-infiltrated tumors 


\begin{tabular}{|c|c|c|}
\hline Feature & $\begin{array}{c}\text { Risk Ratio }(95 \% \\
\text { C.I.) }\end{array}$ & $\begin{array}{c}p- \\
\text { Value }\end{array}$ \\
\hline Age at diagnosis & $1.02(0.83,1.25)^{1}$ & 0.848 \\
\hline \multicolumn{3}{|l|}{ Sex } \\
\hline Female & 1.0 (ref) & \\
\hline Male & $0.83(0.49,1.42)$ & 0.504 \\
\hline \multirow[t]{2}{*}{ Tumor-infiltrating lymphocytes per 10HPF [stage adjusted] } & $0.79(0.68,0.91)^{2}$ & 0.001 \\
\hline & {$[0.81(0.70-0.95)]^{2}$} & [0.008] \\
\hline \multicolumn{3}{|l|}{ Tumor histologic differentiation } \\
\hline Well or moderate & 1.0 (ref) & \\
\hline Poor & $1.53(0.85,2.75)$ & 0.158 \\
\hline \multicolumn{3}{|l|}{ Primary tumor } \\
\hline $\mathrm{T} 1$ & 1.0 (ref) & \\
\hline $\mathrm{T} 2$ & $2.36(0.27,20.34)$ & 0.434 \\
\hline $\mathrm{T} 3$ & $6.30(0.86,46.01)$ & 0.070 \\
\hline $\mathrm{T} 4$ & $9.03(1.14,71.44)$ & 0.037 \\
\hline \multicolumn{3}{|l|}{ Regional lymph nodes } \\
\hline Nx and No & 1.0 (ref) & \\
\hline N1 & $2.16(1.01,4.61)$ & 0.047 \\
\hline N2 & $3.20(1.39,7.37)$ & 0.006 \\
\hline N3 & $5.66(2.16,14.86)$ & $<0.001$ \\
\hline \multicolumn{3}{|l|}{ Distant metastases } \\
\hline M0 & 1.0 (ref) & \\
\hline M1 & $3.34(1.97,5.66)$ & $<0.001$ \\
\hline \multicolumn{3}{|l|}{ AJCC tumor stage } \\
\hline I & 1.0 (ref) & \\
\hline II & $2.98(0.58,15.43)$ & 0.192 \\
\hline III & $5.21(1.22,22.29)$ & 0.026 \\
\hline IV & $11.26(2.69,47.22)$ & $<0.001$ \\
\hline \multicolumn{3}{|l|}{ Lauren classification } \\
\hline Intestinal and mixed & 1.0 (ref) & \\
\hline Diffuse & $1.30(0.77,2.19)$ & 0.335 \\
\hline \multicolumn{3}{|l|}{ Ming classification } \\
\hline Expanding & 1.0 (ref) & \\
\hline Infiltrative & $3.20(1.76,5.83)$ & $<0.001$ \\
\hline \multicolumn{3}{|l|}{ Gastric carcinoma with lymphoid stroma } \\
\hline No & 1.0 (ref) & \\
\hline Yes & $0.24(0.03,1.76)$ & 0.161 \\
\hline \multicolumn{3}{|l|}{ EBV status } \\
\hline Negative & 1.0 (ref) & \\
\hline Positive & $1.44(0.52,4.02)$ & 0.482 \\
\hline \multicolumn{3}{|l|}{ MLH-1 status } \\
\hline Positive (non-microsatellite instability high) & 1.0 (ref) & \\
\hline \multirow[t]{2}{*}{ Negative (microsatellite instability high) [stage adjusted] } & $0.36(0.13,0.84)$ & 0.021 \\
\hline & {$[0.36(0.14-0.91)]$} & [0.032] \\
\hline
\end{tabular}

\footnotetext{
${ }^{1}$ Risk ratio represents a 10 -year increase in age.

${ }^{2}$ Risk ratio represents a 1-unit increase in tumor-infiltrating lymphocytes on the natural logarithmic scale.
}

that show improved survival. In an analogous fashion, lymphoepithelioma-like carcinomas in other anatomic sites may represent the extreme end of a

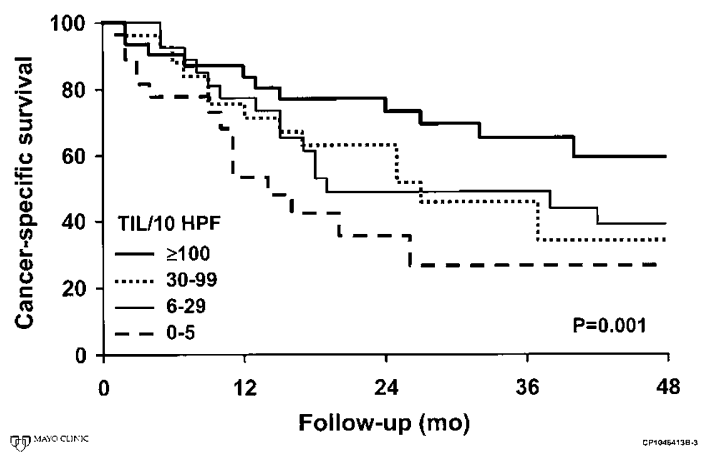

FIGURE 6. Kaplan-Meier survival curve showing survival differences between groups of gastric cancer cases categorized by tumor-infiltrating lymphocyte (TIL) count. spectrum of tumors that show a host immune response, with the factors contributing to the induction of this response dependent on the anatomic site as well as geographic factors.

This study has demonstrated that an increasing tumor-infiltrating lymphocyte count in gastric carcinoma is significantly associated with an increasingly improved survival. EBV positivity and the microsatellite instability-high phenotype account for significant, but clinicopathologically distinct, subsets of lymphocyte-rich gastric cancer; however, these factors are not themselves independent prognosticators. Identification of molecular alterations common to these subsets of tumors that lead to the development of an effective host immune response may provide insight into gastric tumorigenesis and possibilities for future therapeutic strategies. 


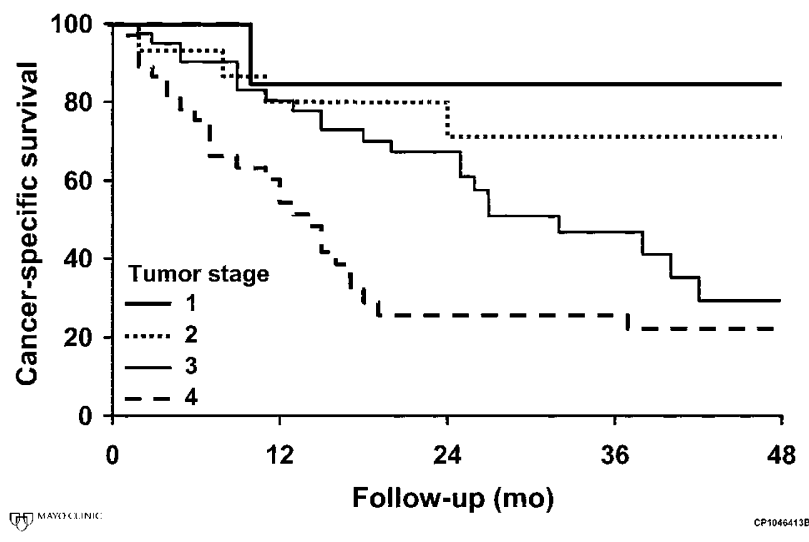

FIGURE 7. Kaplan-Meier survival curve showing cancer-specific survival by stage for 110 gastric cancer cases.

TABLE 5. Multivariate Associations with Death from Gastric Cancer

\begin{tabular}{ccc}
\hline Feature & $\begin{array}{r}\text { Risk Ratio } \\
(95 \% \text { C.I. })\end{array}$ & $p$-Value \\
\hline $\begin{array}{c}\text { Log of tumor-infiltrating } \\
\text { lymphocytes } \\
\begin{array}{c}\text { MLH-1 negative (microsatellite } \\
\text { instability high) }\end{array}\end{array}$ & $0.82(0.71,0.96)^{1}$ & 0.013 \\
\hline
\end{tabular}

${ }^{1}$ Risk ratio represents a 1-unit increase in tumor-infiltrating lymphocytes on the natural logarithmic scale.

\section{REFERENCES}

1. Watanabe H, Enjoji M, Imai T. Gastric carcinoma with lymphoid stroma: its morphologic characteristics and prognostic correlations. Cancer 1976;38:232-43.

2. Minamoto T, Mai M, Watanabe K, Ooi A, Kitamura T, Takahashi Y, et al. Medullary carcinoma with lymphocytic infiltration of the stomach. Cancer 1990;66:945-52.

3. Davessar K, Pezzullo JC, Kessimian N, Hale JH, Jauregui HO. Gastric adenocarcinoma: prognostic significance of several pathologic parameters and histologic classifications. Hum Pathol 1990;21:325-32.

4. Wu M, Shun CT, Wu CC, Hsu TY, Lin MT, Chang MC, et al. Epstein-Barr virus-associated gastric carcinomas: relation to H. pylori infection and genetic alterations. Gastroenterology 2000;118:1031-8.

5. Nakamura S, Ueki T, Yao T, Ueyama T, Tsuneyoshi M. Epstein-Barr virus in gastric carcinoma with lymphoid stroma. Cancer 1994;73:2239-49.

6. Burke AP, Yen TSB, Shekitka KM, Sobin LH. Lymphoepithelial carcinoma of the stomach with Epstein-Barr virus demonstrated by polymerase chain reaction. Mod Pathol 1990;3: 377-80.

7. Shibata D, Tokunaga M, Uemura Y, Sato E, Tanaka S, Weiss L. Association of Epstein-Barr virus with undifferentiated gastric carcinomas with intense lymphoid infiltration. Am J Pathol 1991;139:469-74.

8. Min KW, Holmquist S, Peiper SC, O’Leary TJ. Poorly differentiated adenocarcinoma with lymphoid stroma (lymphoepitheliomas-like carcinomas of the stomach). Am J Clin Pathol 1991;96:219-27.

9. Matsunou H, Konishi F, Hori H, Ikeda T, Sasaki K, Hirose Y, et al. Characteristics of Epstein-Barr virus-associated gastric carcinoma with lymphoid stroma in Japan. Cancer 1996;77: 1998-2004.

10. Chapel F, Fabiani B, Davi F, Raphael M, Tepper M, Champault G, et al. Epstein-Barr virus and gastric carcinoma in Western patients: comparison of pathologic parameters and p53 expression in EBV-positive and negative tumors. Histopathology 2000;36:252-61.

11. Wang $\mathrm{HH}, \mathrm{Wu}$ MS, Shun CT, Wang HP, Lin CC, Lin JT. Lymphoepithelioma-like carcinoma of the stomach: a subset of gastric carcinoma with distinct clinicopathologic features and high prevalence of Epstein-Barr virus infection. Hepatogastroenterology 1999;46:1214-9.

12. Mori M, Wantanabe M, Tanaka S, Mimori K, Kuwano H, Sugimachi K. Epstein-Barr virus-associated carcinomas of the esophagus and stomach. Arch Pathol Lab Med 1994;118: 998-1001.

13. Dos Santos NR, Seruca R, Constancia M, Seixas M, SobrinhoSimoes M. Microsatellite instability at multiple loci in gastric carcinoma: clinicopathologic implications and prognosis. Gastroenterology 1996;110:38-44.

14. Leung SY, Yuen ST, Chung LP, Chu KM, Wong MP, Branicki FJ, Ho JCI. Microsatellite instability, Epstein-Barr virus, mutation of type II transforming growth factor $\beta$ receptor and BAX in gastric carcinoma in Hong Kong Chinese. Br J Cancer 1999;79:582-8.

15. Halling KC, Harper J, Moskaluk CA, Thibodeau SN, Petroni GR, Yustein AS, et al. Origin of microsatellite instability in gastric cancer. Am J Pathol 1999;155:205-11.

16. Oliveira C, Seruca R, Seixas M, Sobrinho-Simoes M. The clinicopathologic features of gastric carcinomas with microsatellite instability may be mediated by mutations of different "target genes." Am J Pathol 1998;153(4):1211-9.

17. Chang MS, Kim WH, Kim CW, Kim YI. Epstein-Barr virus in gastric carcinomas with lymphoid stroma. Histopathology 2000;37:309-15.

18. Adachi Y, Yoh R, Konishi J, Iso Y, Matsumata T, Kasai T, et al. Epstein-Barr virus-associated gastric carcinoma. J Clin Gastroenterol 1996;23(3):207-10.

19. Tokunaga M, Land CE, Uemura Y, Tokudome T, Tanaka S, Sato E. Epstein-Barr virus in gastric carcinoma. Am J Pathol 1993;143:1250-4.

20. Shibata D, Weiss LM. Epstein-Barr virus-associated gastric adenocarcinoma. Am J Pathol 1992;140:769-74.

21. Maxwell GL, Risinger JL, Alvarez AA, Barrett JC, Berchuk A. Favorable survival associated with microsatellite instability in endometrioid endometrial cancers. Obstet Gynecol 2001; 97(3):417-22.

22. Wu CW, Chen GD, Jiang KC, Li AFY, Chi CW, Lo SS, et al. A genome-wide study of microsatellite instability in advanced gastric carcinoma. Cancer 2001;92:92-101.

23. Sepulveda AR, Santos AC, Yamaoka Y, Wu L, Gutierrez O, Kim JG, et al. Marked differences in the frequency of microsatellite instability in gastric cancer from different countries. Am J Gastroenterol 1999;94:3034-8.

24. Shin KH, Park JG. Microsatellite instability is associated with genetic alteration but not with low levels of expression of the human mismatch repair proteins hMSH2 and hMLH1. Eur J Cancer 2000;36:925-31.

25. Peltomaki P. Deficient DNA mismatch repair: a common etiologic factor for colon cancer. Hum Mol Genet 2001;10: 735-40.

26. Choi SW, Choi JR, Chung YJ, Kim KM, Rhyu MG. Prognostic implications of microsatellite genotypes in gastric carcinoma. Int J Cancer 2000;89:378-83.

27. Hayden JD, Cawkwell L, Quirke P, Dixon MF, Goldstone AR, Sue-Ling $\mathrm{H}$, et al. Prognostic significance of microsatellite instability in patients with gastric carcinoma. Eur J Cancer 1997;33:2342-6.

28. Thibodeau SN, French AJ, Roche PC, Cunningham JM, Tester DJ, Lindor NM, et al. Altered expression of hMSH2 and hMLH1 in tumors with microsatellite instability and genetic alterations in mismatch repair genes. Cancer Res 1996;56:4836-40. 
29. Chung YJ, Kim KM, Choi JR, Choi SW, Rhyu MG. Relationship between intratumor histologic heterogeneity and genetic abnormalities in gastric carcinoma with microsatellite instability. Int J Cancer 1999;82:782-8.

30. Kang GH, Kim BH, Lee JT, Shim YH, Gong G, Ro JY. Gross type-matched study of clinicopathologic features of advanced gastric carcinoma with replication error. Pathol Int 1999;49:1053-9.

31. Ottini L, Palli D, Falcetti M, D’Amico C, Amorosi A, Saieva C, et al. Microsatellite instability is associated with tumor location and family history in a high-risk population from Tuscany. Cancer Res 1997;57:4523-9.

32. Marcus VA, Madlensky L, Gryfe R, Kim H, So K, Millar A, et al. Immunohistochemistry for hMLH1 and hMSH2: a practical test for DNA mismatch repair-deficient tumors. Am J Surg Pathol 1999;23:1248-55.

33. Terdiman JP, Gum JR, Conrad PG, Miller GA, Weinberg V, Crawley SC, et al. Efficient detection of hereditary nonpolyposis colorectal cancer gene carriers by screening for tumor microsatellite instability before germline genetic testing. Gastroenterology 2001;120:21-30.

34. Lindor NM, Burgart LJ, Leontovich O, Goldberg RM, Cunningham JM, Sargent DJ, et al. Immunohistochemistry versus microsatellite instability testing in phenotyping colorectal tumors. J Clin Oncol 2002;20(4):1043-8.

35. Sakata K, Tamura G, Endoh Y, Ohmura K, Ogata S, Motoyama T. Hypermethylation of the hMLH1 gene promoter in solitary and multiple gastric cancers with microsatellite instability. Br J Cancer 2002;12:564-7.

36. Chang K, Chen Y, Shibata D, Weiss L. Description of an in situ hybridization methodology for detection of Epstein-Barr virus RNA in paraffin embedded tissues with a survey of normal and neoplastic tissues. Diagn Mol Pathol 1992;1:246-55.

37. Halling $\mathrm{K}$, Roche $\mathrm{P}$. Immunohistochemical analysis for hMLH1 and hMSH2 expression in colorectal cancer. In:
Colorectal cancer methods and protocols. Towatana, NJ: Humana Press; 2000.

38. Dolcetti R, Viel A, Doglioni C, Russo A, Guidoboni M, Capozzi E, et al. High prevalence of activated intraepithelial cytotoxic T lymphocytes and increased neoplastic cell apoptosis in colorectal carcinomas with microsatellite instability. Am J Pathol 1999;154:1805-13.

39. Eerola AK, Soini Y, Paakko P. A high number of tumorinfiltrating lymphocytes are associated with small tumor size, low tumor stage, and a favorable prognosis in operated small cell lung carcinoma. Clin Cancer Res 2000;6:1875-81.

40. Lyle S, Salhany KE, Elder DE. TIA-1 positive tumorinfiltrating lymphocytes in nevi and melanomas. Mod Pathol 2000;13:52-5.

41. Marsigiliante S, Biscozzo L, Marra A, Nicolardi G, Leo G, Lobreglio GB, et al. Computerised counting of tumor infiltrating lymphocytes in 90 breast cancer specimens. Cancer Lett 1999;139:33-41.

42. Yakirevich E, Ben Izhak O, Rennert G, Kovacs ZG, Resnick MB. Cytotoxic phenotype of tumor infiltrating lymphocytes in medullary carcinoma of the breast. Mod Pathol 1999;12: $1050-6$.

43. Thibodeau SN, Bren G, Schaid D. Microsatellite instability in cancer of the proximal colon. Science 1993;260:816-9.

44. Jass JR, Do KA, Simms LA, Iino H, Wynter S, Pillay P, et al. Morphology of sporadic colorectal cancer with DNA replication errors. Gut 1998;42:673-9.

45. Risio M, Reato G, di Celle PF, Fizzotti M, Rossini FP, Foa R. Microsatellite instability is associated with the histological features of the tumor in nonfamilial colorectal cancer. Cancer Res 1996;56:5470-4.

46. Smyrk TC, Watson P, Kaul K, Lynch HT. Tumor-infiltrating lymphocytes are a marker for microsatellite instability in colorectal carcinoma. Cancer 2001;91:2417-22. 